\title{
Positive Mental Health Three Years After East Azerbaijan Earthquake: A Comparative Study
}

\author{
Hassan Rafiey ${ }^{1}$, Fardin Alipour ${ }^{1 *}$, Yahya Salimi ${ }^{2}$, Shokoufeh Ahmadi ${ }^{3}$, Mostafa Mardani', Masoumeh Sayad ${ }^{1}$
}

1. Social Welfare Management Research Center, Department of Social Welfare, University of Social Welfare and Rehabilitation Sciences, Tehran, Iran

2. Department of Epidemiology and Biostatistics, School of Public Health, Kermanshah University of Medical Sciences, Kermanshah, Iran

3. Department of Health in Emergency and Disaster, University of Social Welfare and Rehabilitation Sciences, Tehran, Iran.

Citation: Rafiey H, Alipour F, Salimi Y, Ahmadi Sh, Mardani M, Sayad M. Positive Mental Health Three Years After East Azerbaijan Earthquake: A Comparative Study. Health in Emergencies \& Disasters Quarterly. 2016; 2(1):33-38. https://doi.org/10.18869/nrip.hdq.2.1.5 https://doi. org/10.18869/nrip.hdq.2.1.33

https://doi.org/10.18869/nrip.hdq.2.1.33

\section{Article info:}

Received: 09 Apr. 2016

Accepted: 26 Jul. 2016

\section{Keywords:}

Positive mental health, Earthquake, Disasters and incidents

\section{ABSTRACT}

Background: Positive mental health is one of the important health concepts, which generally evaluates people's emotional, psychological, and social well-being. The current study aimed at investigating positive mental health status in East Azerbaijan earthquake survivors.

Materials and Methods: In this study, a sample of 600 rural adult survivors of East Azerbaijan earthquake were selected by multistage sampling method. Data were collected using positive mental health questionnaire and demographic checklists through face-to-face interview. To analyze data, different statistical tests, including $t$ test were used.

Results: Findings of the current study showed no significant difference between the mean scores of positive mental health and its social subscales in the studied villages. However, the mean scores of emotional well-being subscale in slightly damaged villages and mean scores of psychological well-being subscale in severely damaged villages were higher and significant $(\mathrm{P}<0.05)$.

Conclusion: Attention to long-term mental and social outcomes is the missing link of health studies in incidents and disasters, which must be considered to recover and enhance mental and social health of survivors of natural disasters at the earliest time after the incidents.

\section{Introduction}

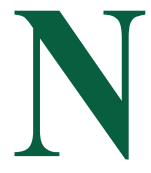

owadays, incidents and disasters are the most important scientific topics and more attention is paid to their different managerial aspects such as prevention, preparation, response, and recovery. Disasters and incidents, at least temporary, suspend mental and social functions, which may even continue over months or years [1].

Our country, due to its geographical location and different vulnerabilities, is at risk of incidents and disasters.
Also, in the field of prevention and recovery from disasters and incidents, especially with regard to mental and social health many major shortcomings exist in the country [2, $3]$. According to the conducted studies on mental and social health in disasters and incidents, the survivors may be involved in different outcomes for a long time. Some of these mental and social outcomes are depression, posttraumatic stress disorder (PSTD), anxiety disorder, decline of social capital, problems associated with occupation, and intensification of other social problems $[2,4]$.

\section{* Corresponding Author:}

Fardin Alipoor, MSc.

Address: Social Welfare Management Research Center, Department of Social Welfare, University of Social Welfare and Rehabilitation Sciences, Tehran, Iran. E-mail: barbodalipour@gmail.com 
Mental health is one of the most important scientific topics, which should be specifically considered in the programs related to the management of disasters and incidents. The World Health Organization (WHO) has provided a definition for mental health, which in some contexts has been adopted as positive mental health due to their close relations. Based on the definition, positive mental health is a state of well-being, through which people can understand their abilities, cope with life stresses, work effectively and productively, and be useful for their community [5].

In other words, positive mental health is a combination of 2 concepts; feeling good in life and emotional health (hedonist views) and positive performance in life (virtue ethics views). Feeling good in life means life satisfaction, happiness, and balance in positive and negative emotions; feeling good in life is beyond the experience of joy and includes social and psychological well-being and positive functioning [6].

Nationwide assessment of adults' mental health (2015), performed on Iranian urban population, reported that $29.8 \%$ of respondents were suspected to have some degrees of mental health disorders; while this figure was $21 \%$ in a similar assessment in 2009 [7]. Positive mental health assessment in the European Union (2005) was low in Italy, Portugal, France, and Sweden, while it was moderate to high in Germany, Spain, and Netherlands [8]. The results indicate that positive mental health status needs more attention in many countries.

Mental health promotion approaches, focusing on positive mental health, aim to enable capabilities of people and communities to achieve and maintain mental health, and reduce barriers towards proper health through creating supportive environments. In other words, this approach emphasizes positive aspects and resources of people and communities; cooperation at all personal, local, and social levels to prevent and reduce mental disorders; and improvement of the coping capacity and quality of life among community members [9].

On the other hand, one of the features of psychological and social problems is their long lasting effects, and many of these outcomes emerge in a longer timeframe, which should be investigated by a scientific study. Ignoring long-term mental and social rehabilitation programs threatens the quality of social life, and has negative outcomes and direct damage to the community.

The current study aimed to evaluate and compare positive mental health status in the severely and slightly damaged rural areas of East Azerbaijan Province, 3 years after the earthquake.

\section{Materials and Methods}

The current study is a part of the project entitled "Evaluating long-term mental and social outcomes of disasters and incidents," endorsed by the Deputy of Research and Technology, University of Welfare and Rehabilitation Sciences in 2015. The current casual-comparative study was conducted in quake-stricken rural areas of East Azerbaijan Province, Iran, 3 years after the event, in 2015. The study population included all quake-stricken villages in East Azerbaijan Province which their dwellers experienced the 2012 earthquake in these areas.

The current study used multi-stage sampling method. First, 20 villages were randomly selected out of the quake-stricken villages. Then, the selected villages were divided into 2 groups of severely affected villages (high loss), and slightly affected villages (low loss), based on the number of causalities in proportion to the village population. Sampling in the villages was also systematically conducted. Accordingly, the number of samples was determined based on the number of families in each village and considering the map of village.

By referring to the families, the questionnaires were completed through interviews. The examiners entered the villages from one direction and using the village map systematically selected the samples based on the number of residential houses. Finally, one person was randomly selected from each family, using Kish method. For this purpose, the examiners, who were mainly local people and had at least a MA degree in psychology and social work, were chosen and sufficiently trained to conduct the interviews. Also an interview guideline that explained all interview details was put at their disposal.

The total sample size was determined based on compare mean paired test and the following assumptions. First, the mean mental disorder prevalence in the general population is $20 \%$ and by assumption that it is $30 \%$ in the earthquake-stricken areas, with confidence interval (IC) of $95 \%$, and power of $75 \%$, the sample size was determined as 300 cases in each group, which was 600 cases in total.

In the current study, the positive mental health questionnaire and a checklist were used as data collection tools. The validity and reliability of the tools had been approved in the previous studies in Iran and other countries [10-12]. Its validity and reliability were approved in this study too, as its Cronbach $\alpha$ was 0.91 . The valid- 
ity of the tool was also approved by the exploratory and confirmatory factor analysis.

\section{Results}

In the current study, $66.2 \%$ and $33.8 \%$ of the respondents were males and females, respectively. The highest (58\%) and lowest $(14.7 \%)$ level of education were observed in the cases with elementary school and higher educations, respectively. The highest (37.3\%) and lowest frequencies were found in the age group of 25-34 and 55-64 years, respectively. Most respondents were farmers and ranchers.

Data analysis results showed that the mean (SD) score of positive mental health in the total population was 29.04(9.02). Also, mean (SD) scores of emotional, social, and psychological well-being subscales were 5.99(2.91), 11.23(4.20), and 11.83(5.07), respectively (Table 1).

To compare the positive mental health status in the study groups, the severely and slightly affected villages, after approving the normality of data by KolmogorovSmirnov and Shapiro-Wilk tests, the data were analyzed using 2 independent samples t test.

According to the results of the present study, the mean scores of positive mental health for the participants of severely and slightly affected villages were 28.87 and 29.22 , respectively. Therefore, the results of 2 independent samples t test showed no significant difference between the 2 groups regarding the mean score of positive mental health $(\mathrm{t}=-3.99 ; \mathrm{P}>0.05)$; but the difference was significant regarding the emotional and psychological subscales $(\mathrm{P}<0.05)$ (Table 2$)$.

\section{Discussion}

The current study was conducted as a part of project entitled "mental and social rehabilitation after disasters and incidents" and aimed to evaluate the long-term mental and social outcomes of August 2012 earthquake in Varzaghan, Ahar, and Heris regions of East Azerbaijan

Table 1. Results of positive mental health assessment in the current study

\begin{tabular}{|c|c|c|c|c|c|c|}
\hline & Number & Minimum & Maximum & Mean & SD & Score \\
\hline $\begin{array}{l}\text { Positive mental } \\
\text { health total score }\end{array}$ & 600 & 3 & 54 & 29.04 & 9.02 & $0-56$ \\
\hline $\begin{array}{l}\text { Emotional well- } \\
\text { being }\end{array}$ & 600 & 0 & 12 & 5.99 & 2.91 & $0-12$ \\
\hline Social well-being & 600 & 0 & 20 & 11.23 & 4.20 & $0-20$ \\
\hline $\begin{array}{l}\text { Psychological } \\
\text { well-being }\end{array}$ & 600 & 0 & 24 & 11.83 & 5.07 & $0-24$ \\
\hline
\end{tabular}

Table 2. Results of the two independent samples $\mathrm{T}$ test to compare positive mental health between the study groups

\begin{tabular}{|c|c|c|c|c|c|c|}
\hline \multirow{2}{*}{ Variable } & \multirow{2}{*}{ Group } & \multirow{2}{*}{ Mean } & \multicolumn{2}{|c|}{ Test for Homogeneity of Variances } & \multicolumn{2}{|c|}{ Test for Equality of Means } \\
\hline & & & $\mathbf{P}$ & $\mathbf{F}$ & $\mathbf{P}$ & $\mathbf{t}$ \\
\hline $\begin{array}{l}\text { Positive mental } \\
\text { health }\end{array}$ & $\begin{array}{l}\text { Severely affected } \\
\text { Slightly affected }\end{array}$ & $\begin{array}{l}28.87 \\
29.22\end{array}$ & 0.704 & 0.402 & 0.470 & 0.63 \\
\hline $\begin{array}{l}\text { Emotional well- } \\
\text { being }\end{array}$ & $\begin{array}{l}\text { Severely affected } \\
\text { Slightly affected }\end{array}$ & $\begin{array}{l}5.21 \\
6.76\end{array}$ & 3.064 & 0.081 & 6.77 & $0.001>$ \\
\hline Social well-being & $\begin{array}{l}\text { Severely affected } \\
\text { Slightly affected }\end{array}$ & $\begin{array}{l}11.21 \\
11.24\end{array}$ & 1.43 & 0.232 & 0.07 & 0.93 \\
\hline $\begin{array}{l}\text { Psychological } \\
\text { well-being }\end{array}$ & $\begin{array}{l}\text { Severely affected } \\
\text { Slightly affected }\end{array}$ & $\begin{array}{l}12.45 \\
11.21\end{array}$ & 3.718 & 0.054 & -2.99 & 0.003 \\
\hline
\end{tabular}


Province, Iran, 3 years post-disaster. The present study was one of the few studies conducted in Iran, which evaluated the long-term mental and social outcomes of disasters and incidents.

Many studies that evaluated the post-disaster mental health outcomes, investigated different aspects of mental disorders. For example, in a study entitled "evaluating prevalence and determinants of depression and posttraumatic stress disorder (PTSD)", 30 months post-disaster among Haiti earthquake adult survivors, the long-term outcomes of earthquake were evaluated using some relevant questionnaires on 1355 subjects. The prevalence of PTSD and depression in the study was $37 \%$ and $26 \%$, respectively and factors such as age, female gender, joblessness, and low education were reported as risk factors for the incidence of depression and PTSD. In addition, predisaster life stresses were also considered as the best predictors for PTSD [13]. In another study in China, the prevalence of PTSD, 8 years after earthquake was reported as $41 \%$ [14]. However, in the current study the positive mental health was evaluated and compared between high-loss and low-loss villages.

The concept of positive mental health was first introduced by Keyes in 2002; he emphasized that mental health should involve social well-being besides psychological and emotional well-being. The positive concept in mental health means a state of well-being, through which people can understand their abilities, cope with life stresses, and have active participation in the community [15]

Positive mental health study is in its infancy and little investigation has been done in this field [16]. Searching domestic databases for the variable of "positive mental health" was fruitless. However, many studies were conducted in this regard and also on general population in the other countries. Some studies developed tools to assess positive mental health [17], and some introduced low positive mental health as a risk factor for mental disorders such as depression [18]. Also, some conducted studies associated lack of positive mental health with increased mortality [16].

In the current study, no significant difference was observed between the positive mental health and its social subscales in the study villages, too. However, emotional well-being subscale score was higher in the slightly affected villages, while psychological well-being was higher in the severely affected villages, and the differences between the scores was significant. This finding can have interesting interpretations. Emotional well-being is more associated with joy and happiness aspects of positive mental health; in other words, its score is related to the flip side of mental disorders (depression and PTSD). It seems that severity and causality of earthquake in vulnerable areas can be considered as strong factors in undermining happiness and joy in the affected people.

On the other hand, psychological well-being was higher in the severely affected areas; which according to the definition, this aspect of mental health was more associated with virtue ethics views of positive mental health (striving for perfection and fulfillment of potential). It might be because of the post-disaster opportunity for growth and development in the affected people. However, for better interpretation, it is necessary to consider the role of other confounding factors. Studies conducted on post-disaster positive mental health status evaluated similar and closely related concepts to positive mental health such as happiness, well-being, etc. Rehdanz et al. (2015) in a study entitled "Effect of natural events and disasters on mental well-being: a case study on Fukushima Tsunami survivors" reported that the level of happiness and mental welfare was lower in the areas closer to the disaster, which had higher causalities, and had a direct relationship with distance from the area of disaster; however, there was no significant difference between the post- and pre-quake general quality of life in the survivors [19].

In another longitudinal study conducted on North China earthquake survivors, psychological well-being and social quality of life were evaluated in the post-quake survivors. In this study, the severity of earthquake was related to different aspects of quality of life; for example, people who were slightly affected by the earthquake and received less post-quake supports showed lower quality of life and psychological well-being. The two mentioned study groups reported different trend of changes over the time. The group which received more support experienced general improvement in recovery in 3 to 9 months intervals, compared to the other group. The study results emphasized the important role of post-disaster variables along with pre-disaster variables on mental and social status after the disaster [20].

\section{Conclusion}

After comparing the results of the studies in different countries with those of the current study, it can be concluded that post-disaster supports between the severely and slightly affected villages was not significantly different to improve positive mental health in the severely affected villages, compared to low-loss villages. On the other hand, some studies showed that different variables such as life satisfaction, occupation, social interaction, 
and so on directly affected positive mental health status. Another explanation with regard to our study results would be the effect of severity and damages of earthquake on such variables and finally positive mental health.

The lower psychological well-being in these areas can be justified by considering the effect of earthquake on these variables, especially missing occupations and failure to achieve job opportunities available in the region after the disaster and on the right time [21]. On the whole, it seems that the mean score differences between different subscales was not enough to produce significant difference in the total score of positive mental health between the groups.

The limitations of the current study were lack of access to pre-earthquake data of the study regions and also difficulties in accessing these regions. To evaluate long-term post-earthquake mental and social outcomes meticulously, a cohort study with a control group is recommended.

\section{Acknowledgments}

This paper has not received any financial support. The authors would like to cordially thank people who participated in this study.

\section{Conflict of Interest}

The authors declared no conflict of interests.

\section{References}

[1] Alipour F, Khankeh HR, Fekrazad H, Kamali M, Rafiey H, Foroushani PS, et al. Challenges for resuming normal life after earthquake: a qualitative study on rural areas of Iran. PLoS Currents. 2014; 6. doi: 10.1371/currents.dis.b4e84b942500e2f8f260f3471b7ee815

[2] Alipour F, Khankeh HR, Fekrazad H, Kamali M, Rafiey H, Ahmadi S. Social capital in post disaster recovery. Health in Emergencies and Disasters. 2015; 1(1):47-54.

[3] Askari A, Rowell K. Prevalence of psychopathology and socio-demographic characteristics among earthquake survivors in Eastern Azerbaijan, Iran. Health in Emergencies and Disasters. 2015; 1(1):9-15.

[4] Wang X, Gao L, Shinfuku N, Zhang H, Zhao C, Shen Y Longitudinal study of earthquake-related PTSD in a randomly selected community sample in north China. American Journal of Psychiatry. 2000; 157(8):1260-6. doi: 10.1176/appi. ajp.157.8.1260

[5] Huppert FA, Wittington J. Positive mental health in individuals and populations. In: Huppert FA, Baylis N, Keverne B, editors. The Science of Well-Being. Oxford: Oxford University Press; 2005.
[6] Keyes CL. The mental health continuum: From languishing to flourishing in life. Journal of Health \& Social Behavior. 2002; 43(2):207-22. doi: 10.2307/3090197

[7] Tavousi M, Haeri MA, Hashemi A, Naghizadeh F, Montazeri A. [Mental health in Iran: A nationwide cross sectional study (Persian)]. Payesh. 2016; 15(30):233-239.

[8] Lehtinen V, Sohlman B, Kovess-Masfety V. Level of positive mental health in the European Union: Results from the Eurobarometer 2002 survey. Clinical Practice and Epidemiology in Mental Health. 2005; 1:9. doi: 10.1186/1745-0179-1-9

[9] Jané-Llopis E, Barry M, Hosman C, Patel V. Mental health promotion works: A review. Global Health Promotion. 2005; 2:9-25.

[10] Joshanloo M, Wissing MP, Khumalo IP, Lamers SM. Measurement invariance of the Mental Health Continuum-Short Form (MHC-SF) across three cultural groups. Personality \& Individual Differences. 2013; 55(7):755-9. doi: 10.1016/j. paid.2013.06.002

[11] Guo C, Tomson G, Guo J, Li X, Keller C, Söderqvist F. Psychometric evaluation of the Mental Health Continuum-Short Form (MHC-SF) in Chinese adolescents: A methodological study. Health and Quality of Life Outcomes. 2015; 13:198. doi: 10.1186/s12955-015-0394-2

[12] Rafiey H, Momtaz YA, Alipour F, Khankeh H, Ahmadi S, Khoshnami MS, et al. Are older people more vulnerable to long-term impacts of disasters? Clinical Interventions in Aging. 2016; 11:1791-95. doi: 10.2147/ cia.s122122

[13] Cénat JM, Derivois D. Assessment of prevalence and determinants of posttraumatic stress disorder and depression symptoms in adults survivors of earthquake in Haiti after 30 months. Journal of Affective Disorders. 2014; 159:111-7. doi: 10.1016/j.jad.2014.02.025

[14] Kadak MT, Nasıroğlu S, Boysan M, Aydın A. Risk factors predicting posttraumatic stress reactions in adolescents after 2011 Van earthquake. Comprehensive Psychiatry. 2013; 54(7):982-90. doi: 10.1016/j.comppsych.2013.04.003

[15] Keyes CL, Dhingra SS, Simoes EJ. Change in level of positive mental health as a predictor of future risk of mental illness. American Journal of Public Health. 2010; 100(12):236671. doi: 10.2105/ajph.2010.192245

[16] Huppert FA, So TT. Flourishing across Europe: Application of a new conceptual framework for defining well-being. Social Indicators Research. 2013; 110(3):837-61. doi: 10.1007/ s11205-011-9966-7

[17] McDowell I. Measuring health: A guide to rating scales and questionnaires. Oxford: Oxford University Press; 2006.

[18] Wood AM, Joseph S. The absence of positive psychological (eudemonic) well-being as a risk factor for depression: A ten year cohort study. Journal of Affective Disorders. 2010; 122(3):213-17. doi: 10.1016/j.jad.2009.06.032

[19] Rehdanz K, Welsch H, Narita D, Okubo T. Well-being effects of a major natural disaster: The case of Fukushima. Journal of Economic Behavior \& Organization. 2015; 116:500-17. doi: 10.1016/j.jebo.2015.05.014

[20] Wang X, Gao L, Zhang H, Zhao C, Shen Y, Shinfuku N. Post-earthquake quality of life and psychological well-being: Longitudinal evaluation in a rural community sample in 
northern China. Psychiatry and Clinical Neurosciences. 2000; 54(4):427-33. doi: 10.1046/j.1440-1819.2000.00732.x

[21] Alipour F, Khankeh H, Fekrazad H, Kamali M, Rafiey H, Ahmadi S. Social issues and post-disaster recovery: A qualitative study in an Iranian context. International Social Work. 2015; 58(5):689-703. doi: 10.1177/0020872815584426 